\title{
A dietary intervention in Bangladesh to counteract arsenic toxicity
}

\author{
J.E.G. Smits ${ }^{1}$, R.M. Krohn ${ }^{1}$, A. Vandenberg ${ }^{2}$ \& R. Raqib ${ }^{3}$ \\ ${ }^{1}$ Faculty of Veterinary Medicine, University of Calgary, Calgary, Alberta, Canada \\ ${ }^{2}$ Department of Plant Sciences, University of Saskatchewan, Saskatoon, Canada \\ ${ }^{3}$ Nutritional Biochemistry Laboratory, Dhaka, Bangladesh
}

\begin{abstract}
This 6-month clinical trial tests whether high-selenium lentils, as a whole food solution, can improve the health of arsenic-exposed Bangladeshi villagers. The study entails 400 participants in two treatment groups. All participating households have tubewell water containing $\geq 100 \mu \mathrm{g} \mathrm{L}^{-1}$, but over $50 \%$ are $>250 \mu \mathrm{g} \mathrm{L}^{-1}$. In this double-blind study, one group is daily consuming high-selenium lentils from the Canadian prairies, the other, low-selenium lentils grown in another ecozone. At the onset, mid-term, and end of the trial, samples (blood, urine, stool, hair) are collected, and health examinations include testing lung inflammation, body weight and blood pressure. The major outcome will be arsenic excretion in urine and feces, and arsenic deposition in hair. Secondary outcomes also include antioxidant status, and blood lipid profile.
\end{abstract}

\section{INTRODUCTION}

Up to 100 million people worldwide are chronically exposed to dangerously high concentrations of arsenic (As) in their drinking water and food supply. Bangladesh is facing contamination of groundwater by As. Since tubewell water contamination by As was discovered in the 1990s, As in drinking water has been reduced by $40 \%$, yet approximately 45 million Bangladeshis remain at risk from As concentrations greater than the WHO guideline value of $10 \mu \mathrm{g} \mathrm{L}^{-1}$ (ppb) in the well water (WHO Fact sheet $N^{\circ} 372$, December 2012) and greater than the Bangladeshi limit of $50 \mu \mathrm{g} \mathrm{L}^{-1}$. Micronutrient-deficient (e.g. selenium) soils lead to less nutritious local foods, which becomes a partner in crime, exacerbating the toxic burden incurred by As exposure.

Selenium (Se) is an important trace element and an antagonist to As toxicity. Se pills are currently used to treat arsenicosis. But pills are not often well received by people and are costly for low-income families. Lentils are a common food in Bangladesh. These lentils are rich in Se, 425$672 \mu \mathrm{g} \mathrm{kg}^{-1}$, which is mostly in the highly bioavailable form, L-selenomethionine (Thavarajah et al., 2007).

The purpose of this work is to determine whether high-Se lentils in the daily diet can decrease the body burden of As in exposed Bangladeshis, when compared to the treatment group on low-Se lentils.

\section{METHODS/EXPERIMENTAL}

This dietary trial is a parallel, randomized, controlled trial (Fig. 1). Four hundred Bangladeshis (approximately 80 families) from Shahrasti area, who have As

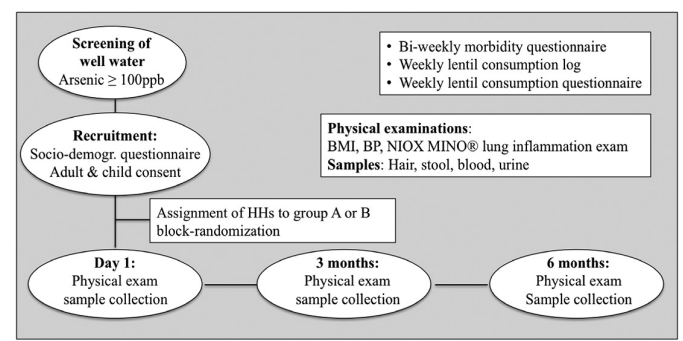

Figure 1. Flow chart of the trial procedures.

levels in the household tubewells $\geq 100 \mu \mathrm{g} \mathrm{L}^{-1}$, were randomly assigned to one of two treatment groups. Eligibility criteria included apparently healthy people aged 14 to 75 years old. In this double-blind study, one group will have high-selenium lentils, the other will consume low-Se lentils.

Each participant is required to eat $65 \mathrm{~g}$ of lentils every day for 6 months. At the beginning, after 3 months, and end of the trial, blood, urine and stool, plus hair (day 1 and at 6 months only) samples are collected. The health examination includes assessment of acute lung inflammation, body weight, height, and blood pressure. The major outcome is As excretion in urine and feces, as well as As deposition in hair. Secondary outcomes include antioxidant status, lipid profile, lung inflammation status and blood pressure.

Arsenic levels in hair, stool and urine samples are measured by Hydride Generation Atomic Absorption Spectrometry (HGAAS). Oxidative stress and antioxidant status is determined by measuring 8OHdG, a major product of ROS-induced oxidative stress, in urine and plasma using ELISA kits. Selenium-dependent glutathione peroxidase uses to 
Table 1. Nutritional analysis of low- and high-Se lentils.

High Se lentils Low Se lentils

\section{Macronutrients}

\begin{tabular}{llrc} 
Protein & \% by weight & 26.22 & 27.73 \\
Starch & \% by weight & 38.00 & 37.00 \\
TDF & \% by weight & 8.48 & 6.66 \\
Fat & \% by weight & 0.78 & 0.77 \\
Ash & \% by weight & 2.77 & 3.16 \\
$\begin{array}{l}\text { Phytochemicals } \\
\text { Phytic acid }\end{array}$ & $\mathrm{g} \mathrm{kg}^{-1}$ & 0.61 & 0.72 \\
$\begin{array}{l}\text { Minerals } \\
\text { Calcium }\end{array}$ & $\mathrm{mg} \mathrm{kg}^{-1}$ & 327.88 & 377.51 \\
Copper & $\mathrm{mg} \mathrm{kg}^{-1}$ & 9.34 & 11.44 \\
Iron & $\mathrm{mg} \mathrm{kg}^{-1}$ & 75.75 & 65.3 \\
Zinc & $\mathrm{mg} \mathrm{kg}^{-1}$ & 42.15 & 51.9 \\
Selenium & $\mathrm{mg} \mathrm{kg}^{-1}$ & 0.854 & 0.029 \\
Arsenic & $\mathrm{mg} \mathrm{kg}^{-1}$ & $<0.001$ & $<0.001$ \\
\hline
\end{tabular}

scavenge reactive oxygen species (ROS), resulting in the production of oxidized GSSG (33). The antioxidant status based on reduced glutathione (GSH) and the oxidized form, GSSG, is determined by the ratio of GSH:GSSG using an ELISA. Triglyceride, total cholesterol, high-density-lipoprotein (HDL), and low-density-lipoprotein (LDL)-cholesterol plus acute phase proteins are measured using a Biochemistry Analyzer Cobas c 311.

\section{RESULTS AND DISCUSSION}

The human dietary study in Bangladesh is under way and early results from the spring of 2016 will be presented. We tested tubewells of 102 households in the Shahrasti region for As. Over 90\% had As $>100 \mu \mathrm{g} \mathrm{L}^{-1}$. The high- and low-Se lentils were grown in the summer of 2014. The macro- and micronutrient content has been determined (Table 1).

We have 4 experimental studies from laboratory animals that showed clear benefits from the high selenium diets.

In rats exposed to As in drinking water, immune function, blood biochemistry, and oxidative stress biomarkers were examined. Liver damage, increased oxidative stress, decreased blood levels of protective antioxidants, and suppressed antibody mediated immunity were the most sensitive health changes from As exposure (Nain \& Smits, 2010). Next, we exposed young, growing rats for 4 months to environmentally realistic levels of As in drinking water. Rats on high
Se diets had higher blood stores of the major antioxidant, glutathione, As-suppressed antibody response was reversed, and body burdens of As were reduced, evident through lower arsenic in the kidneys, and higher fecal and urinary arsenic excretion in animals on high Se diets (Sah \& Smits, 2012).

In an atherosclerotic mouse model, mice were fed high- or low-Se lentil diets for 13 wk while consuming low levels of As in their drinking water $\left(200 \mu \mathrm{g} \mathrm{L}^{-1}\right)$. Arsenic-triggered plaques were formed in the aorta. Plaque development was significantly reduced or completely abolished in aortas of mice on the high Se lentil diet. Our study also indicated that Se deficiency plus As exposure resulted in higher low-density lipoproteins (LDLs), the so-called 'bad' cholesterol (Krohn et al., 2016).

\section{CONCLUSIONS}

The responses from our animal studies, plus those in which Se pills have been advocated for improving health status in As exposed people, are the driving force behind our human dietary study.

Physiological responses and health benefits in humans on the high Se lentil diets will be evident through blood pressure changes, favorable changes in blood triglyceride composition, decreased markers of oxidative stress, plus increased excretion of arsenic, compared with the group on the low Se lentils.

\section{ACKNOWLEDGEMENTS}

We thank Gene Arganosa and Barry Goetz for the lentil nutrient analysis.

\section{REFERENCES}

Krohn, R., Lemaire, M., Negro Silva, L., Mann, K. \& Smits. J.E. 2016. High-selenium lentil diet protects against arsenic-induced atherosclerosis in mice. J. Nutr. Biochem. 27: 9-15.

Nain, S. \& Smits, J.E.G. 2010. Pathological, immunological and biochemical biomarkers of sub-chronic arsenic toxicity in experimental rats. Environ. Toxicol. 27: 244-254.

Sah, S. \& Smits, J.E. 2012. Dietary selenium fortification: a potential solution to chronic arsenic toxicity. Toxicol. Environ. Chem. 94(7): 1-13.

Thavarajah, D., Vandenberg, A., George, G. \& Pickering, I. 2007. Selenium species in selenium-rich lentils from Saskatchewan. J. Agric. Food Chem. 55(18): 7337-7341. WHO 2012. Fact sheet $N^{\circ} 372$, December 2012, World Health Organoization, Geneva. 